\title{
Duodenal Contents Reflux can Induce Esophageal Squamous Cell Carcinoma as Well as Adenocarcinoma
}

\author{
Mukaisho K*, Nakayama T, Yamamoto H, Hagiwara T, Sugihara H and Hattori T \\ Department of Pathology, Division of Molecular Diagnostic Pathology, Shiga University of Medical Science, Seta- \\ tsukinowa-cho, Otsu, Shiga, Japan
}

*Corresponding author: Mukaisho K, Department of Pathology, Division of Molecular Diagnostic Pathology, Shiga University of Medical Science, Seta-tsukinowa-cho, Otsu, Shiga 520-2192, Japan, E-mail: mukaisho@ belle.shiga-med.ac.jp

Citation: Mukaisho K, Nakayama T, Yamamoto H, Hagiwara T, Sugihara H, et al. (2014) Duodenal Contents Reflux can Induce Esophageal Squamous Cell Carcinoma as Well as Adenocarcinoma. J Cancer Sci Clin Oncol 1(1): 103. doi: 10.15744/2394-6520.1.103

Received Date: September 23, 2014 Accepted Date: December 02, 2014 Published Date: December 04, 2014

List of abbreviations: ESCC-Esophageal Squamous Cell Carcinoma; EAC-Esophageal Adenocarcinoma; GERD-Gastroesophageal Reflux Disease

\section{Introduction}

Esophageal carcinoma is the eighth most common cancer, and the sixth most common cause of cancer-related deaths worldwide [1]. Esophageal carcinomas in developing nations account for more than $80 \%$ of the total cases and deaths [1]. Esophageal cancer can arise as esophageal squamous cell carcinoma (ESCC) or esophageal adenocarcinoma (EAC), which have distinct etiological and pathological characteristics. ESCC is the most common histological type of esophageal cancer in the Eastern world, and its incidence remains stable [2,3]. In contrast, the epidemiology of esophageal cancer in developed nations has dramatically changed over the past 40 years. Forty years ago, ESCC accounted for more than $90 \%$ of esophageal cancer cases in the United States. However, adenocarcinoma has now become the leading type of esophageal cancer in the United States, representing $80 \%$ of cases $[4]$.

The currently accepted paradigm is that Barrett's esophagus, in which intestinal-type columnar cells replace reflux-damaged squamous cells, arises as a complication of symptomatic gastroesophageal reflux disease (GERD) and predisposes the patient to EAC [5]. Although GERD has not generally been considered to be a risk factor for ESCC, we discuss the potential relationship between ESCC and the duodenal contents based on recent contributions to the literature and our own experimental results in animal models.

\section{Risk factors for esophageal squamous cell carcinoma}

It is widely accepted that ESCC is associated with tobacco smoking and alcohol consumption [6,7]. The mechanism by which the combination of tobacco and alcohol increases the risk of esophageal cancer has been extensively studied. Aromatic amines, nitrosamines, polycyclic aromatic hydrocarbons, aldehydes, and phenols are among the various carcinogens in tobacco smoke [8]. Alcohol can damage the cellular DNA by decreasing metabolic activity within the cell and therefore impairing detoxification function while promoting oxidation [9]. Alcohol is a solvent, specifically of fat-soluble compounds. Therefore, the hazardous carcinogens within tobacco smoke are able to penetrate the esophageal epithelium more easily [10].

From another perspective, it has been reported that tobacco smoking and alcohol abuse decrease lower esophageal motility, delay gastric emptying, and increase gastric secretion [11-15]. The refluxogenic effects of smoking and alcohol abuse induce gastroduodenal reflux, which may be associated with the development of ESCC. In addition to smoking and alcohol abuse, several recent studies have demonstrated an association between ESCC and duodenal contents reflux or non-acid reflux [16-19], suggesting that this may also be a causative factor for ESCC. Furthermore, there is evidence that gastrectomy is also associated with the subsequent development of distal esophageal cancer [20-22], and symptomatic duodenogastric reflux is the most common postgastrectomy syndrome $[23,24]$. 


\section{Lessons from animal experiments: Association between esophageal squamous cell carcinoma and duodenal contents reflux}

Gastric acid and bile acids are major noxious agents in refluxed gastric juice. They contribute to the development of Barrett's esophagus and could be involved in its progression to EAC $[25,26]$. To study the histogenesis of Barrett's esophagus and EAC, several rat duodenal and gastroduodenal contents reflux models have been developed. These models are created through surgical procedures. Representative models are shown in Figure 1. Interestingly, both ESCC and EAC can develop in these animal models without any known carcinogens [27-31] (Figure 2,3). Furthermore, we previously reported the development of ESCC with thoracic dissemination and metastases to the lung and lymph nodes using the rat reflux model presented in Figure 1b [30] (Figure 3b,3c). We also established an esophageal cancer cell line (ESCC-DR) that was derived from the metastatic tumor in a rat reflux model [30] (Figure $3 \mathrm{~d}$ ). These findings indicate that duodenal contents reflux plays an important role in ESCC carcinogenesis and can induce ESCC with highly malignant behavior.

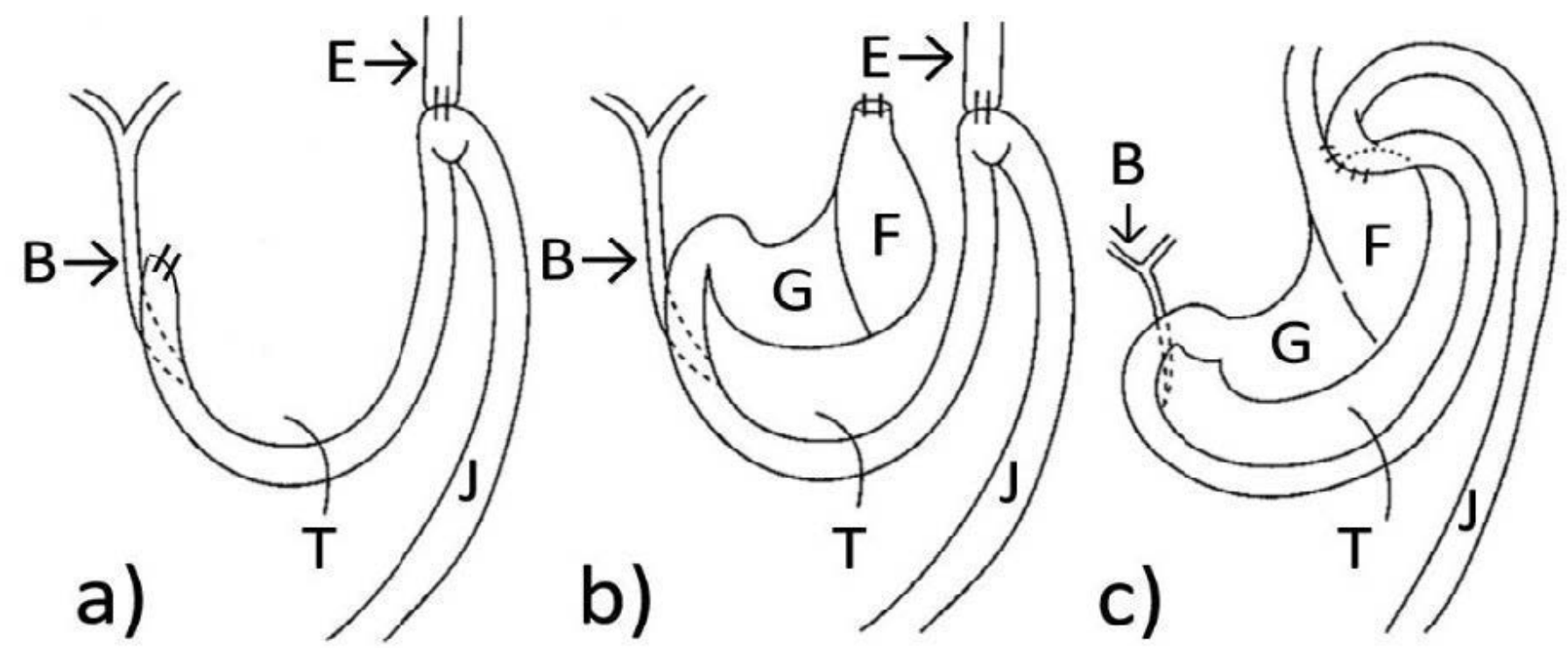

Figure 1: Representative rat duodeno- and gastroduodeno-reflux models

B-Bile duct; F-forestomach; E-esophagus; G-glandular stomach; T-treitz ligament; J-jejunum

(a) Esophago-jejunal anastomosis after total gastrectomy, (b) esophago-jejunal anastomosis without gastrectomy, (c) esophagogastro-jejunal anastomosis
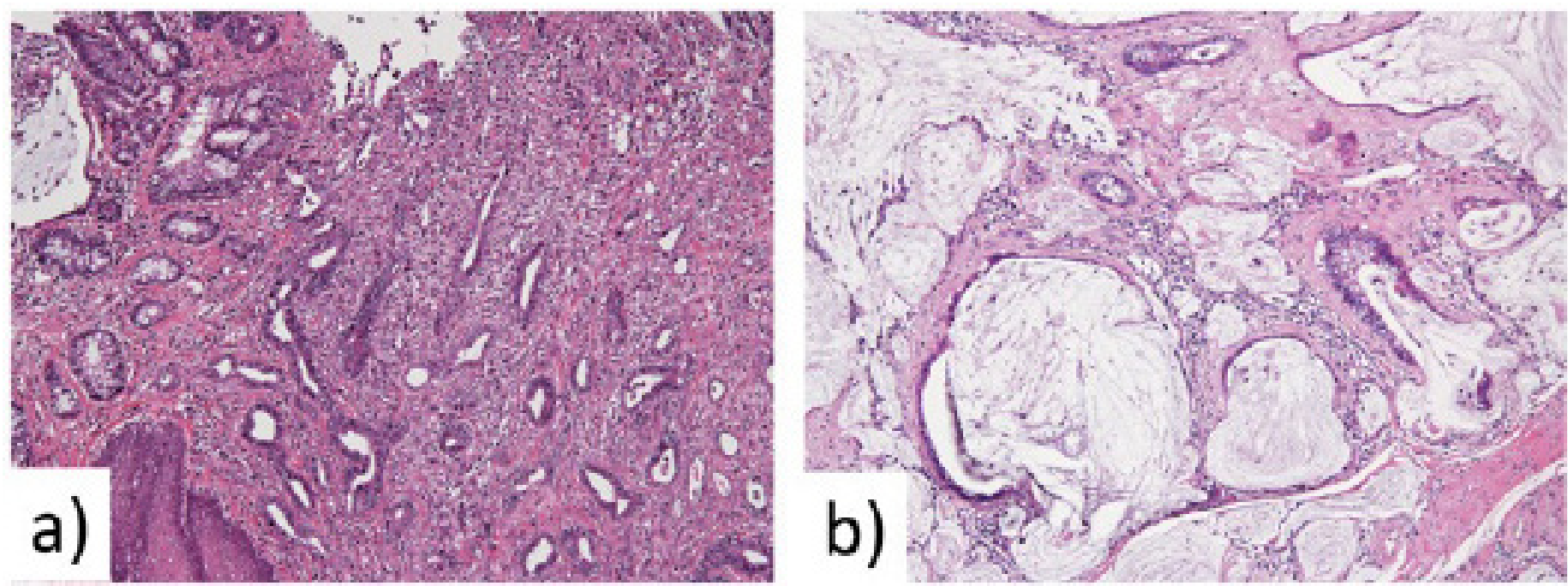

Figure 2: Adenocarcinoma developed in the rat reflux models

(a) Well-differentiated adenocarcinoma, (b) mucinous adenocarcinoma 

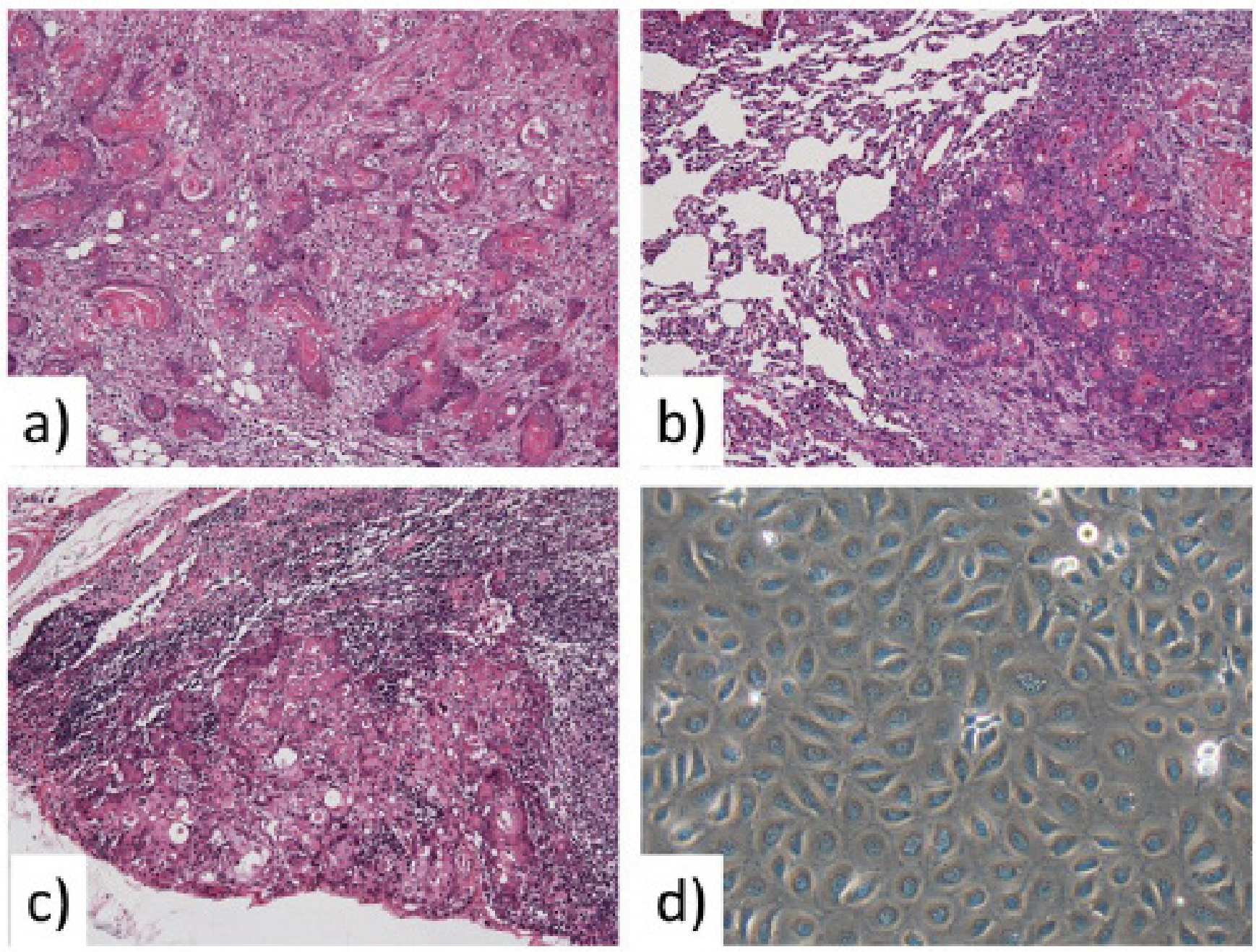

Figure 3: Malignant behavior of squamous cell carcinoma developed in the rat reflux models

(a) Well-differentiated squamous cell carcinoma (SCC), (b) lung metastasis of SCC, (c) lymph node metastasis of SCC, (d) an esophageal cancer cell line (ESCC-DR)

\section{Factors that determine whether reflux-induced damage heals through squamous regeneration or through the development of Barrett's esophagus}

Chronic reflux esophagitis induced by GERD is a pro-inflammatory condition and the main risk factor for the development of Barrett's esophagus and its progression to EAC. In reflux esophagitis, damaged squamous cells are usually replaced by the regeneration of more squamous cells. However, in some individuals, the damaged cells heal through Barrett's esophagus [26]. Huo et al. reported that both gastric acid and bile acids induce CDX2 mRNA and protein expression in esophageal squamous cells from patients with Barrett's esophagus, but not in those from patients who have GERD without Barrett's esophagus [26]. Notably, CDX2 mRNA and protein expression plays a key role in the development of Barrett's esophagus. Huo et al. proceeded to speculate that differences among individuals determine whether reflux-induced damage heals through squamous regeneration or through the development of Barrett's esophagus [26]. They also noted that it remains unclear whether those differences are heritable or acquired [26].

Miyashita et al. recently reported that the severity of duodenoesophageal reflux in rats is related to the development of different histological types of esophageal carcinoma. In brief, EAC was induced by high exposure to duodenal contents reflux and ESCC was induced by low exposure to duodenal contents reflux [16]. In an earlier study, Miwa et al. used duodenoesophageal reflux models to determine that ESCC developed in locations that are distant from the anastomosis, as compared with EAC [31]. These findings also suggest that small but continuous quantities of reflux contents might be associated with the development of ESCC. On the other hand, we reported that high dietary animal fat changed the bile-acid composition and increased the concentration of taurine conjugates in the bile juice. These increased bile acids promoted the development of Barrett's esophagus and Barrett's dysplasia leading to EAC, but tended to decrease the ratio of ESCC in the duodenal contents reflux models [29]. Nehra et al. assayed the bile acids from esophageal samples of 10 asymptomatic patients and 30 patients with symptoms of GERD, using 15-h continuous esophageal aspiration with simultaneous $\mathrm{pH}$ monitoring and modified high-performance liquid chromatography [32]. They reported that, of the primary bile acids, only taurocholic acid was significantly increased in the Barrett's esophagus or stricture group [33]. Thus, dietary components may affect the histological types of esophageal carcinoma in patients with GERD. 


\section{STAT3 (one of the key molecules in the intrinsic inflammatory pathway) is overexpressed in esophageal squamous cell carcinoma}

Chronic inflammation can be linked to carcinogenesis through two pathways: 1) the extrinsic pathway, in which non-neoplastic clinical conditions cause local tissue inflammation that promotes cancer development and 2) the intrinsic pathway, in which precancerous cells acquire a series of growth-promoting genetic abnormalities, some of which also induce an inflammatory microenvironment that contributes to cancer development [33]. Zhang et al. reported activation of the IL-6/STAT3 signalling pathway in transformed Barrett's cells, which enabled them to resist apoptosis induced by bile acid exposure. The authors proceeded to suggest that molecules of the intrinsic inflammatory pathway might play an important role in the development of EAC [34]. On the other hand, activation of STAT3 through inflammatory cytokines in mouse models has been implicated in the development of esophageal cancers, including ESCC and EAC [35,36]. Further, a recent study that examined STAT3-Tyr705 phosphorylation (pSTAT3) in 49 ESCCs and 61 EACs revealed preferentially activated pSTAT3 in ESCC ( $p=0.013)$ [37]. In our animal experiments using duodenal reflux models, STAT3 was overexpressed in ESCC cells (Figure 4). These findings suggest that the intrinsic inflammatory pathway associated with duodenal contents reflux also plays an important role in ESCC carcinogenesis.

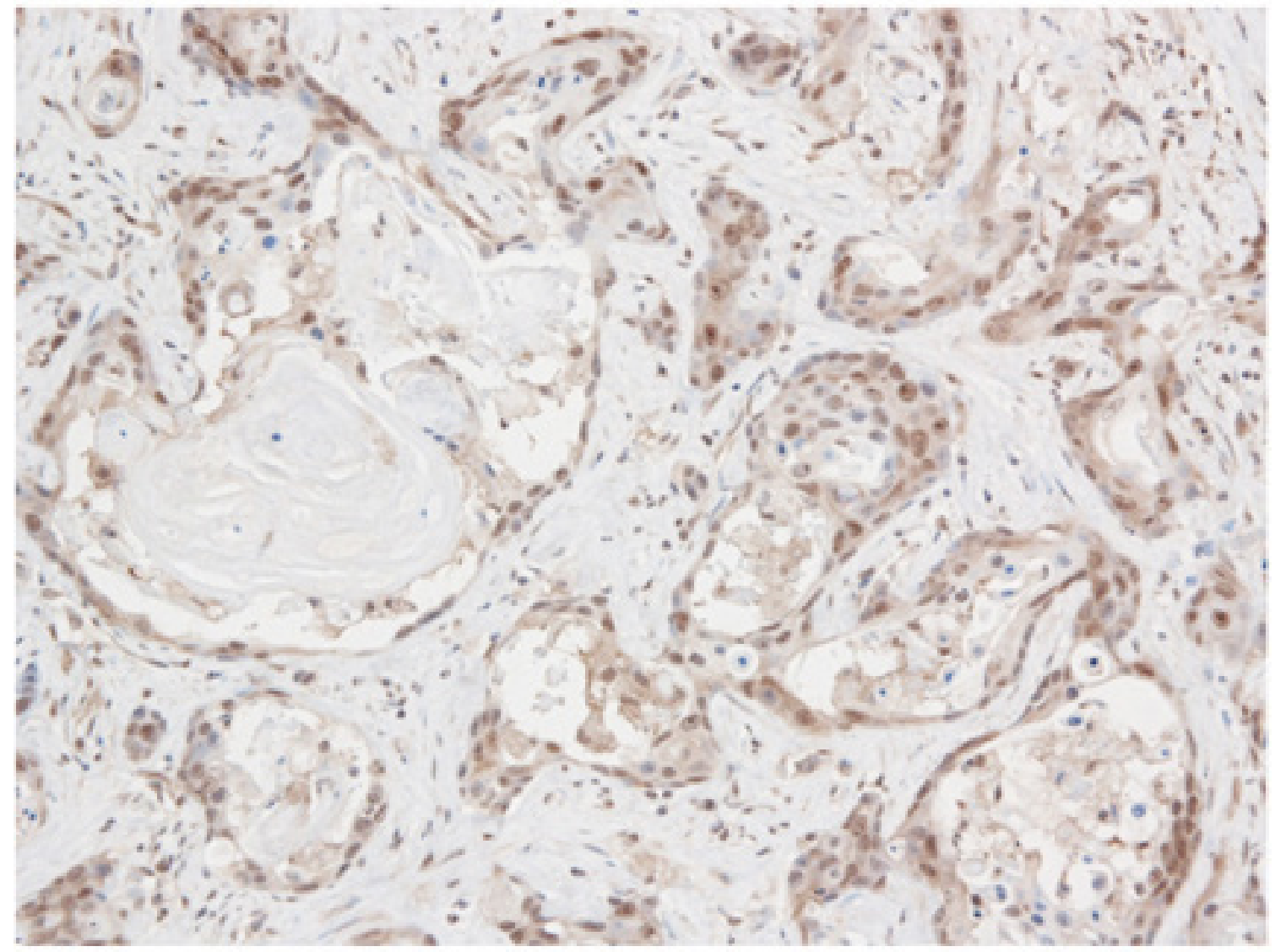

Figure 4: Immunohistochemical staining of STAT3

Overexpression of STAT3 is detected in ESCC cells developed in the rat duodenal contents reflux model Positive sites were visualised by diaminobenzidine (brown)

\section{Conclusion}

Duodenal contents reflux, including bile acids reflux, can induce both ESCC and EAC. The incidence of esophageal cancer differs considerably according to geographic location, racial differences, and dietary components, which can be linked to differences in exposure to risk factors. Whether chronic reflux induces EAC or ESCC may depend on the volume and/or composition of the bile acids in reflux agents.

\section{References}

1. Herszényi L, Tulassay Z (2010) Epidemiology of gastrointestinal and liver tumors. Eur Rev Med Pharmacol Sci 14: 249-58.

2. Parkin DM, Bray F, Ferlay J, Pisani P (2001) Estimating the world cancer burden: Globocan 2000. Int J Cancer 94: 153-6.

3. Hongo M, Nagasaki Y, Shoji T (2009) Epidemiology of esophageal cancer: Orient to Occident. Effects of chronology, geography and ethnicity. J Gastroenterol Hepatol 24: 729-35.

4. Absi A, Adelstein DJ, Rice T ((2013) Esophageal Cancer. The Cleveland Clinic Foundation. 
5. Reid BJ, Li X, Galipeau PC, Vaughan TL (2010) Barrett's oesophagus and oesophageal adenocarcinoma: time for a new synthesis. Nat Rev Cancer 10: 87-101. 6. Nozoe T, Korenaga D, Kabashima A, Sugimachi K (2002) Smoking-related increase of O(6)-methylguanine-DNA methyltransferase expression in squamous cell carcinoma of the esophagus. Cancer Lett 184: 49-55.

7. Yokoyama A, Ohmori T, Muramatsu T, Higuchi S, Yokoyama T, et al. (1996) Cancer screening of upper aerodigestive tract in Japanese alcoholics with reference to drinking and smoking habits and aldehyde dehydrogenase-2 genotype. Int J Cancer 68: 313-6.

8. Napier KJ, Scheerer M, Misra S (2014) Esophageal cancer: A Review of epidemiology, pathogenesis, staging workup and treatment modalities. World J Gastrointest Oncol 6: 112-20.

9. Muwonge R, Ramadas K, Sankila R, Thara S, Thomas G, et al. (2008) Role of tobacco smoking, chewing and alcohol drinking in the risk of oral cancer in Trivandrum, India: a nested case-control design using incident cancer cases. Oral Oncol 44: 446-54.

10. Blot WJ, McLaughlin JK, Fraumeni JF (2006) Esophageal Cancer Cancer Epidemiology and Prevention ( $3^{\text {rd }}$ edn) Oxford University Press, UK.

11. Dennish GW, Castell DO (1971) Inhibitory effect of smoking on the lower esophageal sphincter. N Engl J Med 284: 1136-7.

12. Smit CF, Copper MP, van Leeuwen JA, Schoots IG, Stanojcic LD (2001) Effect of cigarette smoking on gastropharyngeal and gastroesophageal reflux. Ann Otol Rhinol Laryngol 110: 190-3.

13. Kadakia SC, Kikendall JW, Maydonovitch C, Johnson LF (1995) Effect of cigarette smoking on gastroesophageal reflux measured by 24-h ambulatory esophageal pH monitoring. Am J Gastroenterol 90: 1785-90.

14. Kaufman SE, Kaye MD (1978) Induction of gastro-oesophageal reflux by alcohol. Gut 19: 336-8.

15. Vitale GC, Cheadle WG, Patel B, Sadek SA, Michel ME, et al. (1987) The effect of alcohol on nocturnal gastroesophageal reflux. JAMA 258: 2077-9.

16. Miyashita T, Miwa K, Fujimura T, Ninomiya I, Fushida S, et al. (2013) The severity of duodeno-esophageal reflux influences the development of different histological types of esophageal cancer in a rat model. Int J Cancer 132: 1496-504.

17. Uno K, Iijima K, Hatta W, Koike T, Abe Y, et al. (2011) Direct measurement of gastroesophageal reflux episodes in patients with squamous cell carcinoma by 24-h pH-impedance monitoring. Am J Gastroenterol 106: 1923-9.

18. Song Q, Liu H, Wang J, Jia Y, Liu Y, et al. (2014) Dinner-to-bed time and post-dinner walk: new potential independent factors in esophageal cancer development. J Cancer Res Clin Oncol 140: 817-21.

19. Ling ZQ, Mukaisho K, Yamamoto H, Chen KH, Asano S, et al. (2010) Initiation of malignancy by duodenal contents reflux and the role of ezrin in developing esophageal squamous cell carcinoma. Cancer Sci 101: 624-30.

20. Hashimoto N, Inayama M, Fujishima M, Ho H, Shinkai M, et al. (2006) Esophageal cancer after distal gastrectomy. Dis Esophagus 19: 346-9.

21. Maeta M, Koga S, Andachi H, Yoshioka H, Wakatsuki T (1986) Esophageal cancer developed after gastrectomy. Surgery 99: 87-91.

22. Shearman DJ, Arnott SJ, Finlayson ND, Pearson JG (1970) Carcinoma of the oesophagus after gastric surgery. Lancet 1: 581-2.

23. Pera M, Trastek VF, Carpenter HA, Fernandez PL, Cardesa A, et al. (1993) Influence of pancreatic and biliary reflux on the development of esophageal carcinoma. Ann Thorac Surg 55: 1386-92.

24. Sears RJ, Champion GL, Richter JE (1995) Characteristics of distal partial gastrectomy patients with esophageal symptoms of duodenogastric reflux. Am J Gastroenterol 90: 211-5.

25. Matsuzaki J, Suzuki H, Tsugawa H, Watanabe M, Hossain S, et al. (2013) Bile acids increase levels of microRNAs 221 and 222, leading to degradation of CDX2 during esophageal carcinogenesis. Gastroenterology 145: 1300-11.

26. Huo X, Zhang HY, Zhang XI, Lynch JP, Strauch ED, et al. (2010) Acid and bile salt-induced CDX2 expression differs in esophageal squamous cells from patients with and without Barrett's esophagus. Gastroenterology 139: 194-203.

27. Kumagai H, Mukaisho K, Sugihara H, Bamba M, Miyashita T, et al. (2003) Cell kinetic study on histogenesis of Barrett's esophagus using rat reflux model. Scand J Gastroenterol 38: 687-92.

28. Kumagai H, Mukaisho K, Sugihara H, Miwa K, Yamamoto G, et al. (2004) Thioproline inhibits development of esophageal adenocarcinoma induced by gastroduodenal reflux in rats. Carcinogenesis 25: 723-7.

29. Chen KH, Mukaisho K, Sugihara H, Araki Y, Yamamoto G, et al. (2007) High animal-fat intake changes the bile-acid composition of bile juice and enhances the development of Barrett's esophagus and esophageal adenocarcinoma in a rat duodenal-contents reflux model. Cancer Sci 98: 1683-8.

30. Chen KH, Mukaisho K, Ling ZQ, Shimomura A, Sugihara H, et al. (2007) Association between duodenal contents reflux and squamous cell carcinoma-establishment of an esophageal cancer cell line derived from the metastatic tumor in a rat reflux model. Anticancer Res 27: 175-81.

31. Miwa K, Sahara H, Segawa M, Kinami S, Sato T, et al. (1996) Reflux of duodenal or gastro-duodenal contents induces esophageal carcinoma in rats. Int J Cancer 67: 269-74.

32. Nehra D, Howell P, Williams CP, Pye JK, Beynon J (1999) Toxic bile acids in gastro-oesophageal reflux disease: influence of gastric acidity. Gut 44: 598-602.

33. Mantovani A, Allavena P, Sica A, Balkwill F (2008) Cancer-related inflammation. Nature 454: 436-44.

34. Zhang HY, Zhang Q, Zhang X, Yu C, Huo X, et al. (2011) Cancer-related inflammation and Barrett's carcinogenesis: interleukin-6 and STAT3 mediate apoptotic resistance in transformed Barrett's cells. Am J Physiol Gastrointest Liver Physiol 300: G454-60.

35. Quante M, Abrams JA, Lee Y, Wang TC (2012) Barrett esophagus: what a mouse model can teach us about human disease. Cell Cycle. 11: 4328-38.

36. Stairs DB, Bayne LJ, Rhoades B, Vega ME, Waldron TJ, et al. (2011) Deletion of p120-catenin results in a tumor microenvironment with inflammation and cancer that establishes it as a tumor suppressor gene. Cancer Cell 19: 470-83.

37. Timme S, Ihde S, Fichter CD, Waehle V, Bogatyreva L, et al. (2014) STAT3 expression, activity and functional consequences of STAT3 inhibition in esophageal squamous cell carcinomas and Barrett's adenocarcinomas. Oncogene 33: 3256-66. 


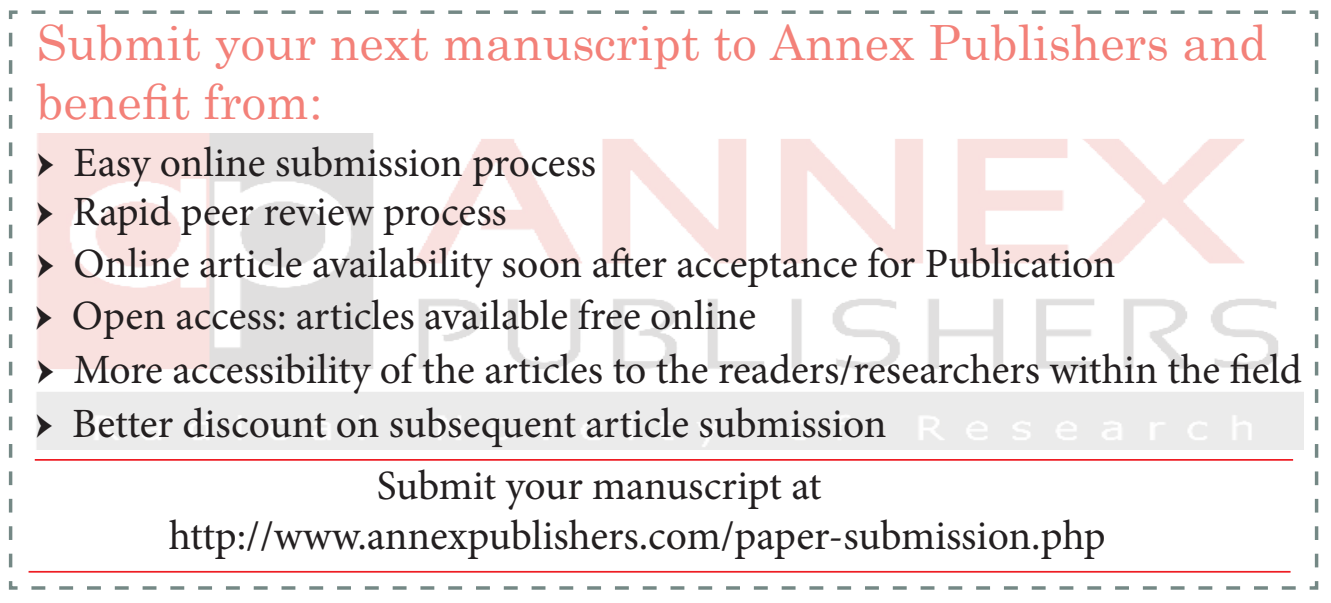

